\title{
The Role of e-Government in Enhancing Postgraduate Employment Transparency in Saudi Arabia
}

\author{
${ }^{1}$ Mohammed Al-Saif, \& ${ }^{2}$ Ahmed Abdel-Whab \\ ${ }^{1}$ Faculty of Business Studies - Arab Open University, Riyadh - Saudi Arabia \\ ${ }^{2}$ Faculty of Computer Studies - Arab Open University, Riyadh - Saudi Arabia \\ ${ }^{2}$ Systems and Computers Engineering Dept. - Faculty of Engineering, Al-Azhar University - Cairo - Egypt \\ Correspondence: Ahmed Abdel-Whab, Faculty of Computer Studies - Arab Open University, Riyadh - Saudi \\ Arabia.
}

Received: July 26, 2021

Accepted: August 20, 2021

Online Published: August 24, 2021

doi:10.5539/cis.v14n4p1

URL: https://doi.org/10.5539/cis.v14n4p1

\begin{abstract}
One of e-Government implementation's most notable advantages is the enhancement of transparency amongst public sector organizations that it brings, possibly caused by the availability of information, the newfound accountability, and the ability to track and monitor transactions within the public sector. With this in mind, the research at hand will centre on the issue of unemployment amongst postgraduates in Saudi Arabia, focusing on reaping the benefits of the centralised, highly efficient e-Government system to control the process of employment within Saudi universities and research centres. In this vein, this research proposes that e-Government (as well as other ICTs) should be tasked with fighting corruption by detailing the specifics and qualifications of the job-seeker in question within the relevant centralised websites. Indeed, such a process would allow for the filtering and selecting process by the employer to be both supervised and audited.
\end{abstract}

Keywords: transparency, unemployment, postgraduates, e-recruitment, corruption, job opportunities

\section{Introduction}

One of Saudi Arabia Vision 2030's main objectives is to increase employment, as well as to ensure equal access to job opportunities via the fostering of transparency amongst public sector organisations-and, indeed, whilst Saudi Arabia did launch the largest scholarship program in history (with more than 60,000 students in over 30 countries worldwide), executed in mind of its ambitious objectives for its graduates, the country did not reap the full benefits of such a program due to minimal transparency amongst the public sector-something that was considered to be an essential challenge in the eyes of the postgraduate student, since this hindered their ability to achieve their dream to contribute to the country's development. With this in mind, the premise of this research is to provide postgraduates with equal opportunity to compete for jobs within these government-based organisations via e-Recruitment systems. Such a process includes supervision and provides the ability for the organisation to select their employees without clear criteria and auditing, subject to external auditing and control for high transparency - and, as would be expected, this leads to current corruption risks. E-Government is described by (Gil \& Martinez, 2007) as a government route using IT to innovatively improve accountability and trust by applying the use of a web-based portal system, and in general, its role is to provide information and public services with accessibility, as well as to observe the performance of a responsive government. E-Government would typically be introduced via five phases of development (i.e., Emerging, Enhanced, Interactive, Transactional, and Connected), each of which demonstrating transparency - as indicated by the fact that the first stage makes available all government information to the general population and the private sector to the last stage allows people to transact with the government and trace their inquiry or complaint (United Nation, 2011; Shahkooh et al., 2008 pp. $1-5$ ).

The previous studies in this field have primarily centred on the advantages of e-Government in terms of its enhancing transparency and empowering citizens from a political perspective, such as in terms of the e-Voting system, and from an economic perspective, such as in terms of the usage of the public e-Procurement mechanism for risk reduction of corruption (Ionescu, 2013). This research, on the other hand, will focus on the problem of unemployment amongst postgraduates in Saudi Arabia, largely concentrating on reaping the benefits of the 
centralised and highly efficient e-Government system. This is with the overall goal of controlling the process of employment within Saudi universities and research centres. Indeed, according to Saudi Vision 2030, 'The nation we aspire to build will not be realised without a grand, collective, national effort where everyone contributes. We all have roles to fulfil, whether we are working in the public, private or non-profit sectors. We will therefore work continually to achieve our hopes and fulfil our aspirations and responsibilities to our country, our society, our families, and to ourselves.' As we can see here, one of the key objectives of Vision 2030 is to increase employment and ensure equal access to job opportunities, which will be done by the fostering of the current levels of transparency amongst public sector organisations. Notably, the e-Government system could be classified into various subsystems that are supportive of the government, in turn even further enhancing their transparency. One of these e-Government subsystems is public e-Recruitment.

Efficient analysis and design of web-based information systems requires modern tools for developing an efficient model; hence, to solve the problem of unemployment amongst postgraduate applicants in Saudi Arabia, this study proposes the establishment of web-based information systems which provide equal opportunities to all applicants. Notably, the building of such systems requires modern tools for analysis and design when it comes to enhancing the ease of use and accessible web-based features for educational institutes and government organisations.

The methodology of the proposed system will follow various stages: first, the gathering of the applicants' information (as well as any data about the educational institutions who are requesting jobs); secondly, the storing of such information in a big data warehouse so it is easy to modify/access when required; thirdly, the nomination of applicants fulfilling the outlined criteria by the proposed system based on the educational institutions' requirements; and, fourthly, the changing of the applicant status by the proposed system changing the status, regardless of whether they were accepted or rejected for the position.

Many statistics based on the recruitment process can be extracted concerning, for example, the number of applicants for postgraduates jobs, the number of applicants nominated by the proposed system, the number of those employed, and the number of rejected applicants (as well as the relevant reasons for rejection).

The organisations who are responsible for the recruitment process can monitor and analyse the information extracted from this proposed system to ensure they are making the correct decisions regarding the future recruitment process for postgraduates.

The main goal of this study is to diminish corruption in employing higher-educated applicants, as well as to foster the current levels of transparency in the e-Recruitment system. To achieve this main goal, we should consider the following objectives:

- Provide the auditing, monitoring, and supervision of the employment process in higher education within the centralised e-Government's subsystem.

- Provide equal opportunities for all candidates to compete for the desired job.

- Guide the rejected candidates so they can identify their shortages and how they can improve their prospects in the future.

- Help decision-makers to identify the general required qualifications for higher education institutions.

- Reduce the expenses associated with student scholarships for the obtaining of degrees that are unsuitable for higher education institutions.

\section{Related Work}

The diffusion of ICT globally has accelerated the need for the transition from paper-based to electronic-based operations amongst government organisations; however, it is important to note that such a transition is not just required for automating transactions at governmental institutes, but also for changing the relation between the public sector and its citizens. This transformation could be viewed in a variety of different forms, such as cost-effective operations, more convenient services, enhanced transparency, anti-corruption, and enhanced accountability (Ndou, 2004 pp. 1 - 24).

One of the most notable advantages of e-Government's implementation is the enhancement of transparency amongst public sector organizations, which is potentially caused by the availability of information, accountability, and the ability to track and monitor the activities occurring within the public sector (Hasani \& Beleraj, 2013 p. 712). Indeed, many international organisations have called for transparency as a way of improving the functioning, accountability, and democratic involvement of the government in their decision-making processes (Arapis \& Reitano, 2018 pp. 550 - 564; Piña \& Avellaneda, 2019, pp. 357 - 382). Notably, transparency can be characterised as the availability and accessibility of information concerning 
government agencies in the sense of public management and governance (Chen, 2019). In the same vein, E-Government implementation provides a partial solution to the issue of corruption, also facilitating the avoidance of arbitrary action and improving the likelihood of detection of corruption by capturing and storing accurate transaction data, making it traceable and linking the corruptor with their wrongdoing.

The relation between e-Government and corruption is well-detailed in the 2003 Global Corruption Report, which notes, 'E-Government offers a partial solution to the multifaceted problem of corruption. It reduces discretion, thereby curbing some opportunities for arbitrary action. It increases the chances of exposure by maintaining detailed data on transactions, making it possible to track and link the corrupt with their wrongful acts. By making rules simpler and more transparent, e-Government emboldens citizens and businesses to question unreasonable procedures and their arbitrary application.' Indeed, whilst the term 'corruption' is still vague and possesses no single agreed definition, one of its most common definitions is, 'Misuse of public position for private benefit' (Nye, 1967 pp. 417 - 427), with some researchers categorising this kind of corruption into 'political corruption' - the opposite of this being 'bureaucratic' or 'administrative' corruption (Andvig et al., 2000) also separate these two variations as 'grand corruption' (political) and 'petty corruption' (bureaucratic or administrative) based on the level of corruption occurring. In a similar vein, (Bardhan, 2006, pp. 341 - 348) claim that whilst politicians are under more scrutiny by citizens than other authority figures, public administrators are usually only held accountable by their supervisors. Meanwhile, another conceptual model proposed by (Srivastava et al., 2016, pp. $511-526$ ) is that which classifies national corruption on two levels: base corruption (observed in national institutions, such as political, legal, and media institutions), and permeated corruption (within national stakeholder service systems, such as business and citizen systems).

Transparency has been considered to be an essential driver for e-Government, as well as e-Government's initiatives, as these are regarded to be powerful schema for enhancing public transparency, along with internal efficiency and quality service delivery (Fountain, 2001; Brown, 1999 pp. 2 - 15).

Another investigation conducted by (Karv, 2015) investigated the impact of e-Government in terms of its reducing corruption, increasing transparency, allowing for better accountability, lauding disappearance of the 'middle man', and its overall bridging the gap between public workers and citizens in Estonia. The research outcome showcased that the so-called 'disappearance of the middle man', followed by the increase in transparency, was the most effective drivers of e-Government. In this regard, (Lopez et al., 2018 pp. 276 - 293) explore in their research the interrelatedness between Spanish local government and e-Government, accountability, and credibility. It asserts the existence of a three-way relationship - namely, that the degree of transparency in a local authority affects the authority's reputation, and that both have an effect on its credibility. Notably, the level of e-Government service offered affects transparency and reputation. As we can see from the above, e-Government is viewed as a positive channel for enhancing trust in the government via government accountability and the empowerment of its citizens (Kauvar, 1998; Friis et al., 2000). E-Recruitment, meanwhile, can only be described as 'the process of any personnel advertising or attracting selected/applying processes via the Internet for external candidates (or the Intranet for internal candidates). The term 'e-Recruitment' is also sometimes dubbed 'online recruitment' or 'Internet recruiting'. Recruitment is defined as, '...those practices and activities carried on by the organisation with the primary purpose of identifying and attracting potential employees' (Barber, 1998). Although the private sector has applied e-Recruitment systems amongst their organisations over the course of the last few years to marry the information age and enhance efficiency, quality, service speed, and the scope of applicant outreach, and to lower the costs of advertising, the e-Recruitment system indeed has some drawbacks, including résumé overload, candidate confidentiality issues, and the diversity of candidate quality (Holm, 2010 pp. $91-111$ ).

Public sectors are required to implement the e-Recruitment system amongst its departments with the aid of the technology revolution as well as the information age to reap the benefits of the system (which has been exploited at the private sector level). Saying this, the features and quality of the e-Recruitment system impact the advantages of that system. Indeed, the e-Recruitment system should not just be used to automate the applications, but also to include data verifications and electronic comparison to guarantee justice amongst candidates. Indeed, the e-Government system, which integrates various applications, could streamline the process of e-Recruitment within the public sector with such accessibility of citizens' information.

\section{Theoretical Background}

We will consider below some of the studies that have presented a proposed solution to building an automated e-Recruitment system and examine how it functions, how it is applied, and the environment in which this proposed system has been used, before finally addressing its benefits and limitations. 
(Evanthia et al., 2012 pp. 551 - 568) provide an automatic classification of candidates based on a set of criteria, relying on the use of four criteria: qualification (in years of formal academic training), work experience (in months), loyalty (average number of months spent per job), and personality. When a position is vacant, the recruiter inserts the weight of each selection criteria into the work position module and sends the position requirements. Here, the applicants' applying for a position in the job application module marks the beginning of the recruitment process starts, and during this process, the applicant can log into the system using its LinkedIn account credential, which allows the system to automatically retrieve from the LinkedIn profile all the relevant parameters required for the applicant's pre-screening. Further, to extract features that match the candidate's personality characteristics, the system examines their personality by asking the applicant to insert his blog URL and, if one is provided, the Personality Mining Module applies linguistic analysis to blog posts. In the system database, the candidate's qualifications, as well as his scores on the application criteria process, are stored, and the applicant ranking module gives the overall rank of the applicants at the final stage of the recruitment process accordingly. Each applicant's rating depicts how well their profile meets the criteria of the recruiter based on the AHP (Analytical Hierarchy Process), which corresponds to the score of the applicants according to the relevant assessment criterion. By altering the weight of the selection criteria, the recruiter will then be able to reassess the applicants. The recruitment process ends with the top applicants' invitation to enter the interview process.

This strategy was proposed and assessed in a large-scale prototype for implementation in the private sector, the final results of this process indicating that it has been effective in recognising and classifying job seekers, providing rejected applicants with fair arguments, as well as recommendations for them to concentrate on concerning reinforcing the qualifying specifications for certain types of work.

Another e-Recruitment system has been developed by Amusan \& Oyediran that includes six key stages in the e-Recruitment process. The first step, which helps to establish work requirements and vacancy descriptions, is the creation of job vacancy details; the second stage is the developing of an online application by logging into the electronic recruitment system and creating a new application; the third stage is the posting of all the job vacancies from the information given in the application to the related websites (based on the closing dates contained in the application); the fourth stage is candidate shortlisting, aimed at evaluating the candidates' online applications after their submitting their CV and declaration of support; the fifth stage schedules interviews with candidates who have passed all the previous stages, providing either an interview or a rejection; and the sixth stage is the contacting of the applicants (Amusan \& Oyediran, 2016 pp. $10-14$ ).

Three different universities have tested this system and supported it with satisfactory results. Notably, the system further reduces the response time required for the recruitment process and helps to reduce the distance between job applicants and job seekers in communication. However, no feedback was provided to rejected applicants to allow them to build and improve their skills and qualifications in the future, meaning it was concluded to be better used in combination with e-Government so the central government can track and control the process of electronic recruitment.

A strategy was proposed by (Kapse et al., 2012 pp. 82 - 86) comprised of three key modules: Administrator, Jobseekers, and Company. The website administrator module has full control over the website, can access and delete all registered users' information, and can change and update the webpages. It can additionally access all the company's details. Meanwhile, the jobseeker's module must be registered with the access scheme for the system; further, their personal details should be checked and their passwords updated. Here, the résumé can also be revised and downloaded by the recruiter. Moreover, the applicant can access the role descriptions the companies are advertising, as well as register and attend online tests. Online testing and the selecting of candidates can be done by the company, as can the posting of the vacancies' details.

The goal of this study was to create a webbased central recruitment process framework allowing for the recruitment process to be connected and efficiently completed by both jobseekers and companies. Incurring reduced times, expenses, and efforts, this system can help to strengthen conventional recruiting and will act as a framework for the recruitment of eligible applicants by both jobseekers and the private sector. The drawback of this system, however, is that it does not offer feedback for applicants excluded from the system, meaning such applicants will not be informed of the reasons behind their exclusion and what they lacked in terms of expertise, skills, and qualifications.

In the same vein, a new framework for extracting the personality traits of candidates based on their use of social media was presented by (Faliagka et al., 2015 pp. 153 - 162). It comprises the below elements:

- Module for Job Application: Input forms that allow applicants to apply for a job vacancy are generated. Here, the applicant has the choice of using his or her Twitter or Facebook credentials to log in to the 
system.

- Personality Mining Module: If an applicant intends to use his/her Facebook or Twitter credentials to log in to the system, the system may be able to gain access to his/her timeline status and engage with other social network contacts.

- Applicant Grading Module: The score of the applicant is calculated according to a number of predefined criteria. The techniques of online mining are used and applied to the applicant's social contact, with the proposed system implementing a ranking method which, based on individual qualification criterion ratings, will decide the overall relevance of candidates to a designated job position. AHP or Machine Learning techniques are notably the basis of such rating functions.

The proposed method will assess the suitability of applicants for a specific position based on of their usage of social networks as a way of defining their personality characteristics. Each applicant is evaluated based on how well-rounded, social, enthusiastic, and successful he/she is based on the information obtained from his/her activities on social media.

This study relied on the presence of a private sector e-Recruitment method, which evaluates candidates through their social media profiles based on their personal characteristics and does not include a human evaluation phase (e.g., a job interview). The study also did not include any input to those who were rejected regarding how they can improve their personal characteristics via their social media accounts use.

\section{Proposed Solution}

As a way to diminish corruption within employment procedures for Saudi Arabian postgraduate applicants, this study attempts to design an efficient subsystem within the e-Government system. Here, an information system that will admit postgraduate applicants for employment via a portal is clearly required — and, indeed, any educational institutions that are seeking such postgraduates should be given the opportunity to select the best elements for their employment and to give such opportunities to distinguished individuals/specialists. In mind of this, the proposed solution is a web interface information system that will allow the candidate to apply for an academic job. The top of the system will be the website pages (which contain all the services provided to the applicants and academic organisations), while the back end of the system will be a database for the storing and retrieving of all the information required for the system.

\subsection{Information-Oriented}

- A system that allows postgraduates to add/edit/update their demographic information (e.g., National ID; name; age; address; contact details; level of education), CV, copy of certificates, and years of experience.

- A system that allows the academic organisation to add/edit/update data for requested jobs for postgraduate applicants.

\subsection{Process-Oriented}

A system that contains the following services:

- Checking applicant data.

- Candidate-selection for jobs.

- Granting jobs.

- Provision of qualifications for non-grantees.

- Generation of statistics and reports.

- Employment monitoring.

\subsection{The System Architecture}

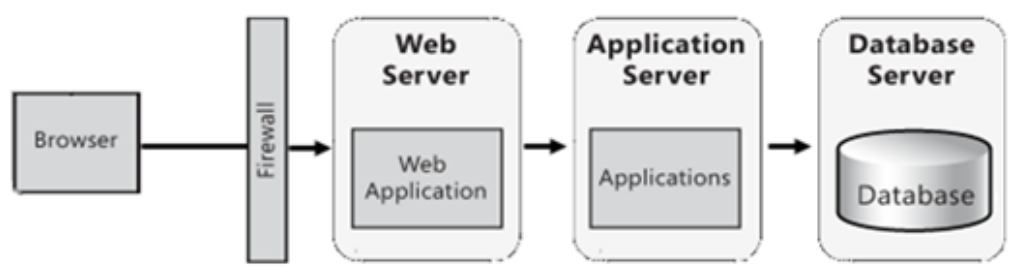

Figure 1. Multi-Tier System Architecture 
Our subsystem uses an n-tier server, the information being stored and retrieved from a database server before being passed back to the application server for processing (the logic tier); then, it is eventually sent to the web application (presentation tier) and the user browser, as shown in Figure 1.

\subsection{E-R Analysis of the Problem Domain}

A given problematic domain is analysed for the purpose of better understanding the domain, as well as to determine the scope of the target by Entity-Relation (E-R) analysis (entities are identified and relations between them are established). The entities and their relations are notably the bases of the system structures, as shown in Figure 2.

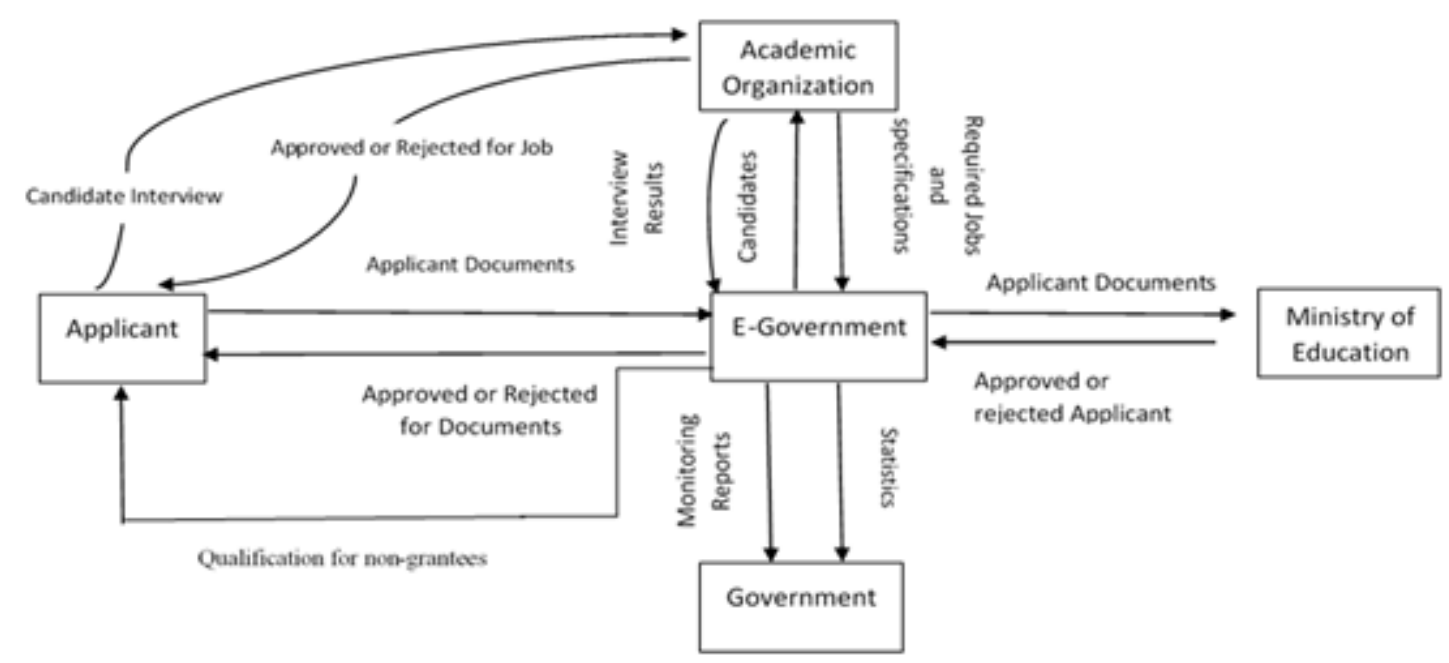

Figure 2. An E-R Diagram for the Proposed System

\subsection{Process Sequence}

The process sequence analysis describes the overall processes within the system, giving a brief description of each process, as shown in Figure 3.

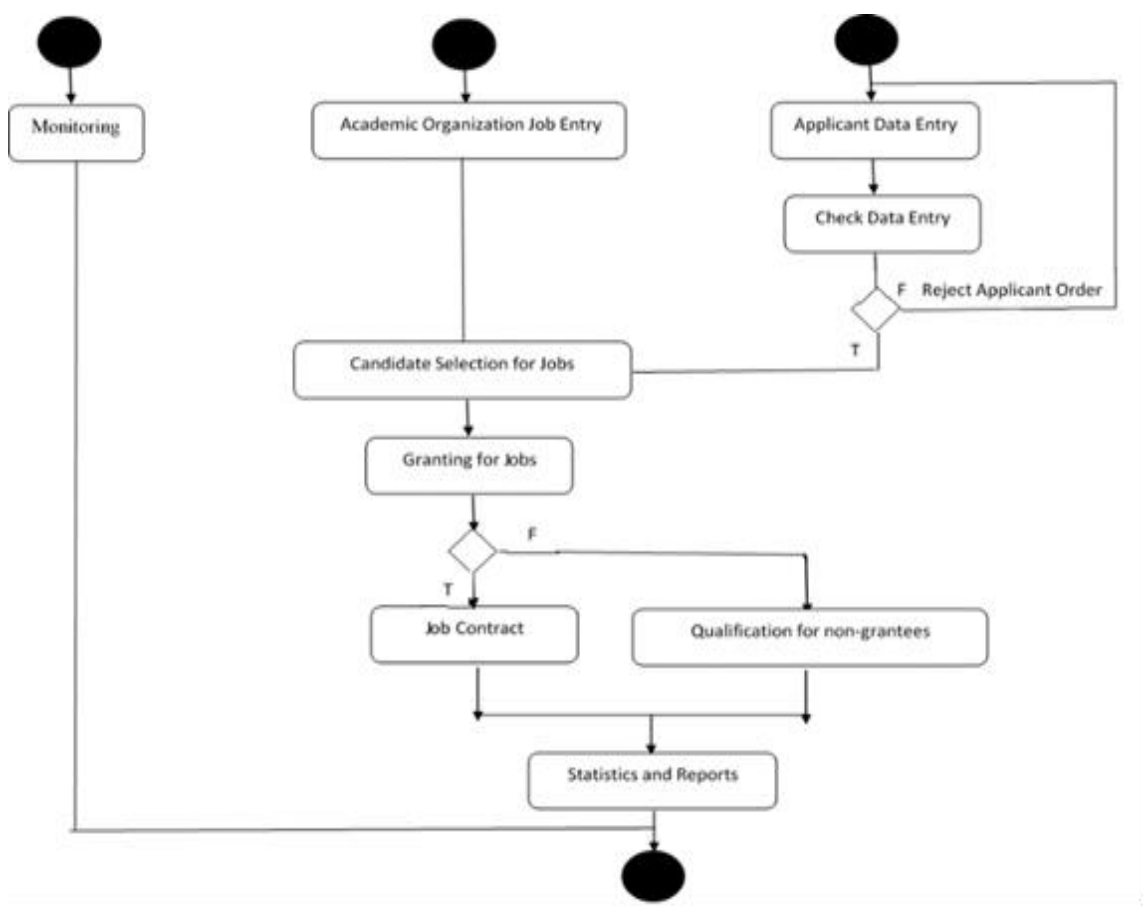

Figure 3. Activity Diagram of the Proposed System 
- Application Data Entry: Applicant data includes the given applicant's demographic information (i.e., National ID; name; age; address; contact details; level of education), their CV, a copy of their certificates, and their years of experience. The applicants can modify their data by accessing his/her data page after entering the username and password issued by the system. The system will put the applicant's status as 'waiting' until their documents are checked.

- Checking Application Data: This is the internal stage within the e-Government system; it checks the identity of the applicant by inquiring about their data from another e-Government subsystem. This is to ensure that the applicant obtains the approved and recognised academic certificates (i.e., a Master's and $\mathrm{PhD}$ ) by the Ministry of Education. If the applicant-checking process is approved, the system transfers its state as 'unemployed'; or, if the applicant-checking process is not approved, the system transfers its status to 'rejected'. In the latter situation, the system informs the applicant of their rejection and specifies the reason why. Rejected applicants can notably update their documents and apply again and change their status to 'waiting'.

- Job Requirements for an Academic Organisation: The academic organisation at hand requests many jobs for the Master's- and PhD-holder that applied through the system. This data form includes the name of the academic institution, the number of jobs the applicant has had, the number of jobs they have had for their Master's, the number of jobs they have had for their $\mathrm{PhD}$, and the required conditions for these jobs.

- Candidate Selection for Jobs: Based on the needs of the academic organisation from the higher education holder, the system will search the database to select the suitable candidates for these jobs. When doing this, the organisation enters the criteria required for these jobs (e.g., the level of education; the main specialisation/sub-specialisation; the age period; the number of years of experience; the granter of the Master and $\mathrm{PhD}$; the country in which the degree was granted; the place of residence of the applicant). The filtering stage will be applied to select the most suitable applicants based on the criteria of the required jobs. In the case of candidacy, the status of the applicant will be changed from 'unemployed' to 'candidate' within the system.

- Granting Jobs: After interviewing the candidates, selecting the most suitable ones, and getting the official contract signed, the organisation updates the system by changing the candidate's status to 'employed'.

- Qualification for Non-Grantees: The organisation must update the system for rejected applicants by detailing the causes for refusal, as well as how which the candidates could develop themselves to obtain a similar job in the future.

- Statistics: The system issues reports and statistics concerning the number of applicants that were granted the job, the number of applicants nominated for the job, and the number of applicants that were rejected from the job.

- Monitoring: The anti-corruption committee within the education ministry has the right to monitor the system, establish the number of jobs that have been offered by the organisations, the number of applicants who have been admitted to these jobs, the number of rejected applicants, and the causes of refusal.

\subsection{Scenario of Actions}

The scenario of actions is detailed for the purpose of describing how each objective can be achieved within different situations in the proposed system, as shown in Table 1. 
Table 1. Scenario of Actions Through the Proposed System

\begin{tabular}{lll}
\hline Entity & Action & WebPage \\
\hline $\begin{array}{l}\text { Applicant } \\
\text { Applicant }\end{array}$ & $\begin{array}{l}\text { Visiting Homepage } \\
\text { Applicant Data Entry }\end{array}$ & $\begin{array}{c}\text { Homepage } \\
\text { Applicant Registration Page } \\
\text { (Basic Data) } \\
\text { Applicant Registration Page } \\
\text { (Documents Entry) }\end{array}$ \\
& Applicant Data Entry (Certificates) & Jobs Required Page \\
Academic Organisation & Jobs Required Entry & Applicant Login Page \\
Applicant & Applicant Login & Employment Tracking Page \\
Applicant & Checking Applicant's Data & Academic Organisation Log \\
Academic Organisation & Academic Organisation Login & in Page \\
& & Jobs Candidate Page \\
Academic Organisation & Candidates Selection for Jobs & Employment Tracking Page \\
Applicant & Applicant Check Status & Jobs Candidate Result Page \\
& & Employment Tracking Page \\
Academic Organisation & Grant or Reject the Candidate for the Job & Query Page \\
Applicant & Applicant Check Status & Reports Page \\
Administrator & Monitor & Statistics Page \\
Administrator & Generate Reports & \\
Administrator & Generate Statistics &
\end{tabular}

\subsection{Website Map}

The website map shows a list of pages within our proposed system, as shown in Figure 4.

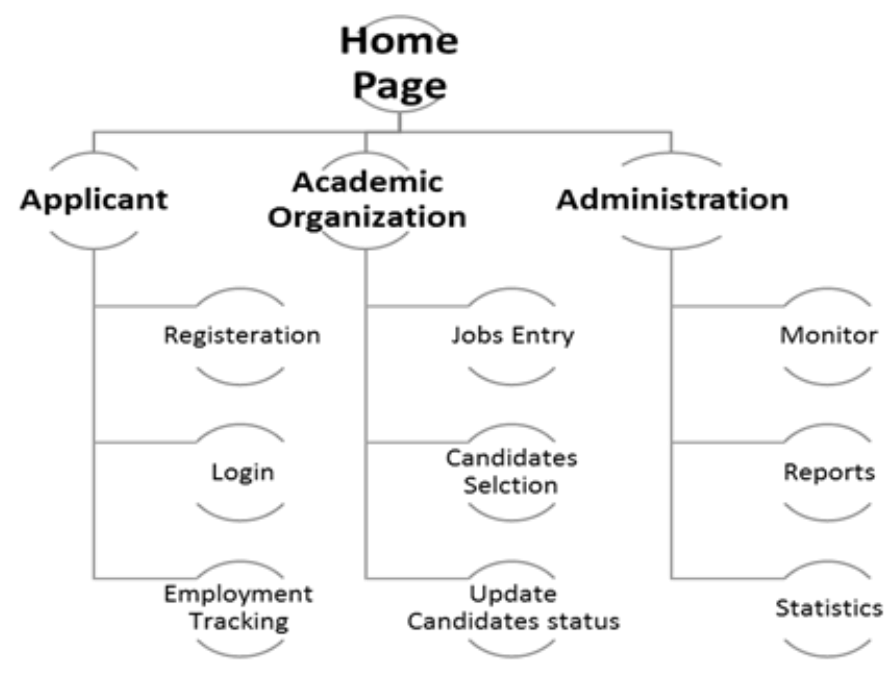

Figure 4. Website Map for the Proposed System

\section{Discussion}

In this study, we have proposed an automated solution for the occupation of academic positions in research centers, colleges, and academic organisations. An e-Government framework would be a suitable solution for the national government's wanting a regulatory and supervisory role. Further, a series of procedures have been suggested for the selection of candidates, these procedures reviewing the submitted applications, selecting the suitable candidates for the job, and then approving the application for those accepted.

This system is characterised by its being a part of the e-Government (public sector) rather than the private sector, as the previous literature has proposed. This system also provides rejected applicants with input with regards the reasons for their rejection, offering them guidance concerning how to develop their skills, experiences, and abilities.

This system is also distinguished by the oversight and monitoring of the national government to ensure that the concept of accountability and justice is implemented during the selection of academic applicants, as well as to help the government to improve the individuals who are willing to work in the academic sector by realising their full potential in terms of experiences and abilities. 


\section{Conclusion}

In this paper, we have addressed the issue of unemployment amongst authorities of higher education who seek academics and research positions. It has proposed a system that provides the higher-degree-holders with equal opportunity to compete for jobs within these academic organisations via e-Recruitment systems.

Our proposed solution is a subsystem of the e-Government that permits higher-degree-holders to present their documents and certificates online. The system then verifies the validity of such documents with aid from the Ministry of Education, additionally allowing academic organisations (e.g., universities; academic research centres) to provide the job data available to them. The proposed system automatically selects applicants who are qualified for these positions to be interviewed, who are instantly notified of their acceptance or rejection, as well as any reasons behind their rejection, if relevant.

The proposed system additionally provides statistics and reports that include the number of applicants, the number of qualified candidates, the number of accepted applicants, and the number of rejected applicants. The system additionally allows the government to monitor all processes to ensure transparency and that the service reaches its beneficiaries.

\section{Acknowledgments}

The Authors would like to thank the Arab Open University for supporting this research paper.

\section{References}

Amusan, D. G., \& Oyediran, M. O. (2016). Development of efficient e-recruitment system for university staff in Nigeria. Circulation in Computer Science, 1(1), 10-14. https://doi.org/10.22632/ccs-2016-251-13

Andvig, J. C., Fjeldstad, O. H., Amundsen, I., \& Søreide, T. (2000). Research on Corruption A policy-oriented survey.

Arapis, T., \& Reitano, V. (2018). Examining the evolution of cross-national fiscal transparency. The American Review of Public Administration, 48(6), 550-564. https://doi.org/10.1177/0275074017706740

Barber, A. E. (1998). Recruiting employees: Individual and organizational perspectives. Sage Publications.

Bardhan, P. (2006). The economist's approach to the problem of corruption. World Development, 34(2), 341-348. https://doi.org/10.1016/j.worlddev.2005.03.011

Brown, D. M. (1999). Information systems for improved performance management. Reinventing government in the information age. International practice in IT-enabled public sector reform, 1(113), 2-15.

Chen, C., \& Han, Y. (2019). Following the money: The political determinants of E-fiscal transparency in US states. Public Management Review, 21(5), 732-754. https://doi.org/10.1080/14719037.2018.1523451

Faliagka, E., Rigou, M., \& Sirmakessis, S. (2015, June). An e-recruitment system exploiting candidates' social presence. In International Conference on Web Engineering (pp. 153-162). Springer, Cham. https://doi.org/10.1007/978-3-319-24800-4_13

Faliagka, E., Tsakalidis, A., \& Tzimas, G. (2012). An integrated e-recruitment system for automated personality mining and applicant ranking. Internet research. https://doi.org/10.1108/10662241211271545

Fountain, J. E. (2001). The virtual state: Transforming American government? National Civic Review, 90(3), 241-252. https://doi.org/10.1002/ncr.90305

Friis, C. S., Demchak, C., \& LaPorte, T. (2000). Webbing governance: national differences in constructing the face of public organizations. In Handbook of public information susytems. Marcel Dekker.

Gil-Garcia, J. R., \& Martinez-Moyano, I. J. (2007). Understanding the evolution of e-government: The influence of systems of rules on public sector dynamics. Government information quarterly, 24(2), 266-290. https://doi.org/10.1016/j.giq.2006.04.005

Hasani, N., \& Beleraj, B. (2013). E-government as an anti corruption tool. The case of Albania. Academic Journal of Interdisciplinary Studies, 2(8), 712. https://doi.org/10.5901/ajis.2013.v2n8p712

Holm, A. B. (2010, May). The effect of e-recruitment on the recruitment process: Evidence from case studies of three Danish MNCs. In Proceedings of the 3rd European academic workshop on electronic human resource management (pp. 91-111).

Ionescu, L. (2013). The impact that e-government can have on reducing corruption and enhancing transparency. Economics, Management, and Financial Markets, 8(2), 210-215. 
Kapse, A. S., Patil, V. S., \& Patil, N. V. (2012). E-recruitment. International Journal of Engineering and Advanced Technology, 1(4), 82-86.

Karv, J. (2015). E-Government and its ability to reduce corruption-The case of Estonia.

Kauvar, G. (1998, October). Electronic government: Concepts, visions, and strategies. In The KAPAs International Symposium on Electronic Government: Visions and Strategies, Seoul, Korea.

López-López, V., Iglesias-Antelo, S., Vázquez-Sanmartín, A., Connolly, R., \& Bannister, F. (2018). E-Government, transparency \& reputation: an empirical study of Spanish local government. Information Systems Management, 35(4), 276-293. https://doi.org/10.1080/10580530.2018.1503792

Ndou, V. (2004). E-Government for developing countries: opportunities and challenges. The electronic journal of information systems in developing countries, 18(1), 1-24. https://doi.org/10.1002/j.1681-4835.2004.tb00117.x

Nye, J. S. (1967). Corruption and political development: A cost-benefit analysis. American political science review, 61(2), 417-427. https://doi.org/10.2307/1953254

Piña, G., \& Avellaneda, C. (2019). Central government strategies to promote local governments' transparency: guidance or enforcement? Public Performance \& Management Review, 42(2), 357-382. https://doi.org/10.1080/15309576.2018.1462215

Shahkooh, K. A., Fasanghari, M., \& Abdollahi, A. (2008, April). Clustering the countries according to relation between e-government and transparency. In 2008 3rd International Conference on Information and Communication Technologies: From Theory to Applications (pp. 1-5). IEEE. https://doi.org/10.1109/ICTTA.2008.4529952

Srivastava, S. C., Teo, T. S., \& Devaraj, S. (2016). You Can't Bribe a Computer: Dealing with the Societal Challenge of Corruption Through ICT. MIS Q., 40(2), 511-526. https://doi.org/10.25300/MISQ/2016/40.2.14

UN (United Nation). (2010). Global E-Government Survey, Leveraging E-government at a Time of Financial and Economic Crisis, economic and social affairs.

\section{Copyrights}

Copyright for this article is retained by the author(s), with first publication rights granted to the journal.

This is an open-access article distributed under the terms and conditions of the Creative Commons Attribution license (http://creativecommons.org/licenses/by/4.0/). 